\title{
Variations in sea surface roughness induced by the 2004 Sumatra-Andaman tsunami
}

\author{
O. A. Godin ${ }^{1,2}$, V. G. Irisov ${ }^{2,3}$, R. R. Leben ${ }^{4}$, B. D. Hamlington ${ }^{4}$, and G. A. Wick ${ }^{2}$ \\ ${ }^{1}$ Cooperative Institute for Research in Environmental Sciences, University of Colorado, Boulder, CO 80309, USA \\ ${ }^{2}$ NOAA/Earth System Research Laboratory, Boulder, CO 80305-3328, USA \\ ${ }^{3}$ ZelTechnology LLC, Boulder, CO 80305, USA \\ ${ }^{4}$ Colorado Center for Astrodynamics Research, University of Colorado, Boulder, CO 80309, USA
}

Received: 19 March 2009 - Revised: 20 June 2009 - Accepted: 28 June 2009 - Published: 16 July 2009

\begin{abstract}
Observations of tsunamis away from shore are critically important for improving early warning systems and understanding of tsunami generation and propagation. Tsunamis are difficult to detect and measure in the open ocean because the wave amplitude there is much smaller than it is close to shore. Currently, tsunami observations in deep water rely on measurements of variations in the sea surface height or bottom pressure. Here we demonstrate that there exists a different observable, specifically, ocean surface roughness, which can be used to reveal tsunamis away from shore. The first detailed measurements of the tsunami effect on sea surface height and radar backscattering strength in the open ocean were obtained from satellite altimeters during passage of the 2004 Sumatra-Andaman tsunami. Through statistical analyses of satellite altimeter observations, we show that the Sumatra-Andaman tsunami effected distinct, detectable changes in sea surface roughness. The magnitude and spatial structure of the observed variations in radar backscattering strength are consistent with hydrodynamic models predicting variations in the near-surface wind across the tsunami wave front. Tsunami-induced changes in sea surface roughness can be potentially used for early tsunami detection by orbiting microwave radars and radiometers, which have broad surface coverage across the satellite ground track.
\end{abstract}

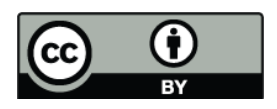

Correspondence to: O. A. Godin (oleg.godin@noaa.gov)

\section{Introduction}

The need for a reliable system for early tsunami detection and warning was made painfully clear by the hundreds of thousands of lives lost to the tsunami generated by the 9.3 magnitude Sumatra-Andaman earthquake that swept the Indian Ocean on 26 December 2004 (Stein and Okal, 2005; Lay et al., 2005; Titov et al., 2005). An early and dependable assessment of a tsunami threat requires detection of the tsunami wave in the open ocean away from the shore (Lautenbacher, 2005; Levin and Nosov, 2005; Bernard et al., 2006; Schindelé et al., 2008). By complementing traditional seismic data and point measurements as provided by the Deep-ocean Assessment and Reporting of Tsunamis (DART) buoys network (González et al., 2005; Bernard et al., 2006), wide-area satellite observations of tsunami manifestations can potentially improve the accuracy and timeliness of tsunami forecasts (Levin and Nosov, 2005; Synolakis and Bernard, 2006; Geist et al., 2007; Wei et al., 2008; Behrens et al., 2008), increase the lead time of tsunami warnings, decrease the probability of false alarms (Walker, 1996; Dudley and Lee, 1998; Godin, 2004; Nagai et al., 2007), and help to avoid unnecessary evacuations (Dudley and Lee, 1998; Bernard et al., 2006). Of the tsunami manifestations in the deep ocean, variations in ocean surface roughness are most relevant to tsunami detection from space provided that these can be revealed by orbiting active (scatterometers) and passive (radiometers) scanning microwave sensors, which have broad surface coverage of hundreds of kilometers across the satellite ground track.

Tsunami-induced variations in surface roughness away from the shore were first observed in visible light (Walker, 1996; Dudley and Lee, 1998) as "tsunami shadows," i.e. extended darker strips on the ocean surface along a tsunami

Published by Copernicus Publications on behalf of the European Geosciences Union. 


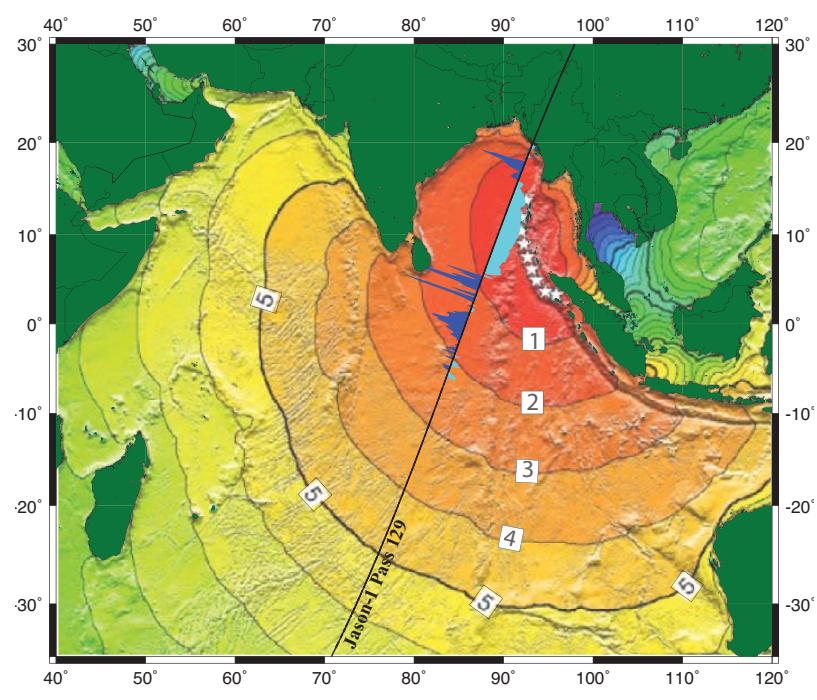

Fig. 1. Jason-1 satellite altimeter overflight of the SumatraAndaman tsunami. The Jason-1 ground track and C-band $\sigma_{0}$ data for pass 129 encountering the Sumatra-Andaman tsunami is superimposed on contours of the tsunami leading wave front at hourly intervals after the earthquake. The $\sigma_{0}$ data are shown for the portion of the ground track where the tsunami wave had arrived. White stars show location of the tsunami wave sources. (Tsunami wave front graphic is courtesy of the National Geophysical Data Center/NOAA, adopted from http://www.ngdc.noaa.gov/ hazard/img/2004_1226.jpg).

front. Formation of the "shadows" as areas with a different root mean square (RMS) surface slope has been tentatively explained theoretically as a result of air-sea interaction; specifically, of tsunami-induced perturbations in the wind velocity close to the ocean surface, which are predicted to be much larger than currents in the tsunami wave (Godin, 2003, 2004; Rowan, 2004). Later theoretical studies (Godin, 2005; Troitskaya and Ermakov, 2008) corroborated these conclusions.

The Sumatra-Andaman tsunami is the first for which detailed concurrent measurements of the sea surface height (SSH) and radar backscattering strength at nadir $\left(\sigma_{0}\right)$ in deep water are available. These measurements were made with microwave radars onboard the Jason-1, Topex/Poseidon, Envisat, and Geosat Follow-on (GFO) altimetric satellites (Smith et al., 2005; Ablain et al., 2006; Gower, 2007). The SSH measurements were used by a number of authors to study the properties of the Sumatra-Andaman tsunami, its propagation and scattering from the coastline as well as to improve characterization of the seismic source of the tsunami and to verify numerical tsunami models (Fine et al., 2005; Kulikov et al., 2005; Smith et al., 2005; Song et al., 2005; Titov et al., 2005; Ablain et al., 2006; Hirata et al., 2006; Kumar et al., 2006; Fujii and Satake, 2007; Gower, 2007; Hayashi, 2008; Hoechner et al., 2008; Sladen and Hébert, 2008). Detection of earlier, weaker tsunamis in less extensive satellite SSH records is discussed by Okal et al. (1999) and Zaichenko et al. (2005).

In this study, we concurrently employ $\sigma_{0}$ data, which are a measure of the ocean surface roughness ( $\mathrm{Fu}$ and Cazenave, 2001), and SSH data obtained by Jason-1 on 26 December 2004 to determine the tsunami effect on surface roughness. Considerable uncertainty remains regarding the magnitude of tsunami-induced roughness variations and the possibility of their detection against the background of potentially stronger roughness variations due to other geophysical processes. Through statistical analyses of multiple years of satellite altimeter observations, here we demonstrate that the Sumatra-Andaman tsunami induced distinctive variations in ocean surface roughness, which are measurable with microwave sensors already in orbit. Previously, $\sigma_{0}$ data obtained by Jason-1 during the Sumatra-Andaman tsunami passage were discussed by Troitskaya and Ermakov (2005, 2008), but without comparison to analogous data in the absence of a tsunami.

The remainder of this paper is organized as follows. Section 2 describes the satellite altimeter data utilized in this research. In Sect. 3, we employ earlier theoretical predictions of tsunami-induced surface roughness variations to model the effect of these variations on satellite altimeter measurements. Section 4 presents results of statistical analyses of various attributes of the satellite altimeter observations, with technical details of our data processing techniques being delegated to Appendices A and B. In Sect. 5, we present conclusions of this work and discuss their implications for early tsunami detection by orbiting microwave radars and radiometers.

\section{Jason-1 data}

Of all the satellite altimeters, Jason-1 provides the earliest observations of the Sumatra-Andaman tsunami and has the most extensive data records. Jason-1 encountered the tsunami $1 \mathrm{~h} 53$ min after the earthquake (Ablain et al., 2006; Gower, 2007) at about $5^{\circ} \mathrm{S}$ heading northeast on ascending path 129 for cycle 109 (Fig. 1). Since the satellite launch in December 2001, an extensive set of high-quality SSH and $\sigma_{0}$ data (Fig. 2) has been accumulated, which allows one to characterize the variability of the radar backscattering strength under various atmospheric conditions when no tsunami is present. Of primary interest in the Jason-1 data set pertaining to the Sumatra-Andaman tsunami overflight is a segment of records between $6^{\circ} \mathrm{S}$ and $2^{\circ} \mathrm{S}$ latitudes (Fig. 3), which contains the leading front of the tsunami. The spatial extent of this segment is of the order of the tsunami wavelength. Understanding of the physical processes on the leading front of a tsunami is of particular importance for tsunami early detection and warning. The tsunami signal is unambiguously present in this segment and is well above the noise level in the SSH records (Fig. 4), which allows for retrieval of information on the spectral content of the tsunami wave. Data 

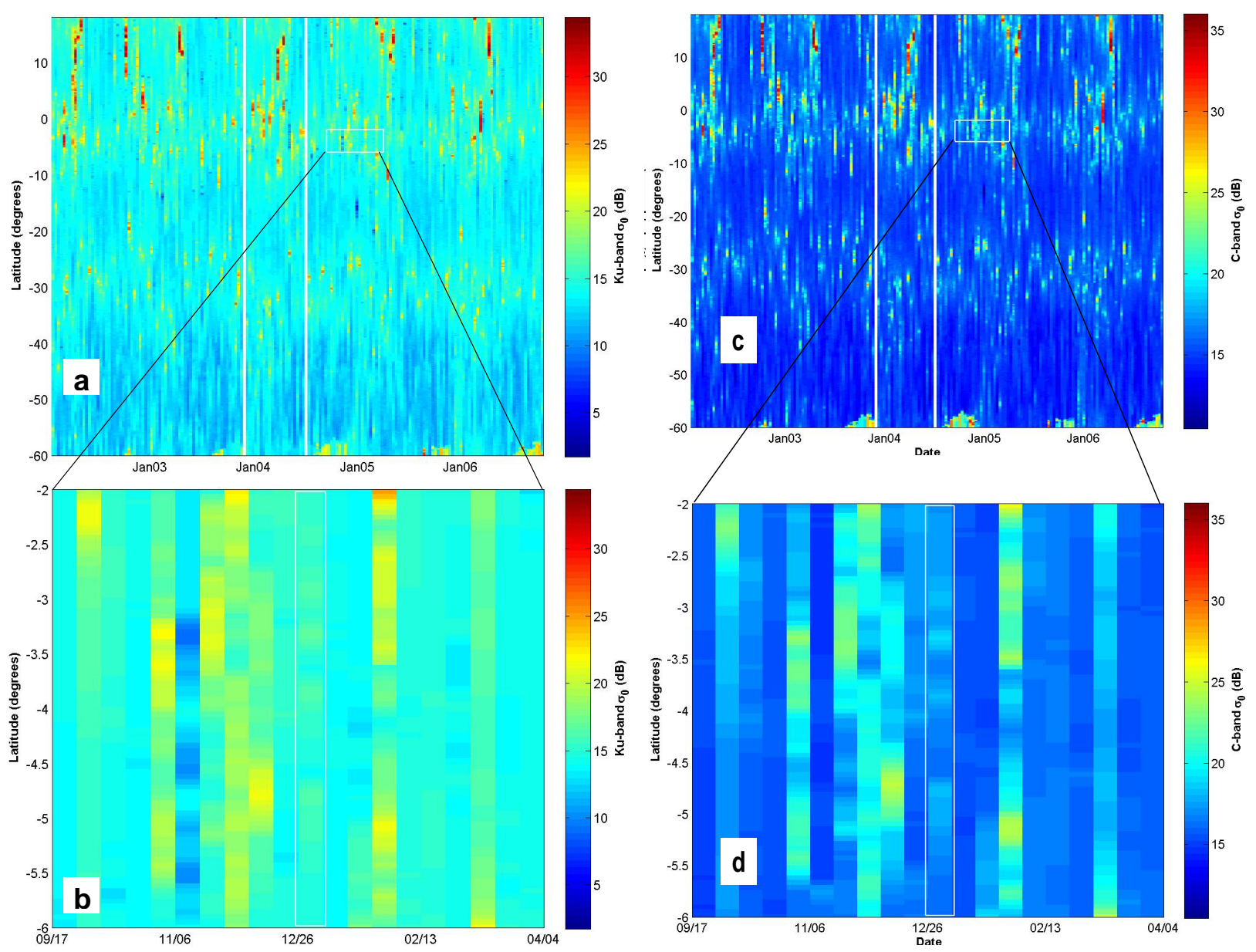

Fig. 2. Radar backscattering strength, $\sigma_{0}$, data from the Jason- 1 altimeter. (a) Ku-band $\sigma_{0}$ values for 10 day repeat cycles 1 through 174 from ascending path 129 from $60^{\circ} \mathrm{S}$ to landfall in the Bay of Bengal. (b) An expanded view of the white frame in panel $a$. The data corresponding to the Sumatra-Andaman tsunami overflight are distinguished by the white frame. (c) Same as in panel $a$ but for C-band $\sigma_{0}$ values. (d) Same as in panel $b$ but for C-band $\sigma_{0}$ values.

quality is high and there are few data points excluded by intrinsic quality controls. Results obtained using this segment of the Jason-1 records are presented in Sect. 4.1.

Radar backscattering strengths measured in the $\mathrm{Ku}$ and $\mathrm{C}$ microwave frequency bands in the vicinity of the tsunami leading front show pronounced, up to $\pm 1 \mathrm{~dB}$, variations which are not present in measurements along the same track on the last passage before and the first passage after the tsunami (Fig. 3b, c). The magnitude and the spatial structure of the $\sigma_{0}$ variations are consistent with theoretical estimates discussed in the next section. However, in and of itself such an agreement does not necessarily mean that the observed $\sigma_{0}$ variations were caused by the tsunami. To positively attribute the observed $\sigma_{0}$ variations to the Sumatra-Andaman tsunami, we show in Sect. 4.1 that these variations have certain exceptional characteristics which distinguish them from the $\sigma_{0}$ variations observed with the same instrument when no tsunami is present.
The Jason-1 records obtained on ascending path 129 for cycle 109 outside the vicinity of the tsunami leading front, i.e. to the south of about $6^{\circ} \mathrm{S}$ and to the north of $2^{\circ} \mathrm{S}$ (Fig. 1), also contain valuable information regarding surface manifestations of the Sumatra-Andaman tsunami. If the exceptional characteristics of $\sigma_{0}$ variations observed in the vicinity of the tsunami leading front are indeed caused by the tsunami wave, no such exceptional features should be observed to the south of about $6^{\circ} \mathrm{S}$, where the wave had not arrived by the time of the Jason- 1 overflight. On the other hand, tsunami manifestations in the radar backscattering strength should extend to the north of $2^{\circ} \mathrm{S}$ as long as the tsunami amplitude remains strong. Analysis of this segment of the record is complicated by increased frequency of data points being excluded by intrinsic quality controls (Fig. 4). Results obtained using the Jason-1 records outside the vicinity of the tsunami leading front are presented in Sect. 4.2. 

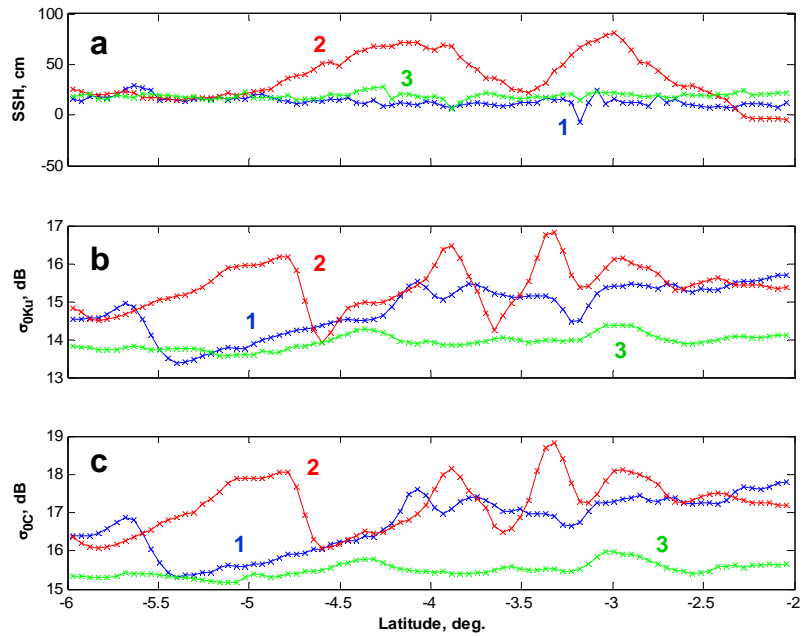

Fig. 3. Jason-1 data for pass 129 from $6^{\circ} \mathrm{S}$ to $2^{\circ} \mathrm{S}$ obtained days before (Cycle 108) (1), coincident with (Cycle 109) (2), and 10 days after (Cycle 110) (3) the Sumatra-Andaman tsunami.(a) Sea surface height. (b) Ku-band radar backscattering strength. (c) C-band radar backscattering strength.

\section{Tsunami-induced wind velocity perturbations}

Long surface gravity waves in the ocean modulate short gravity and gravity-capillary waves and change ocean surface roughness through the interaction of short waves with nearsurface currents and variations of near-surface wind induced by long waves (Hara and Plant, 1994; Troitskaya, 1994; Kudryavtsev et al., 1997; Cohen and Belcher, 1999; Godin and Irisov, 2003). For a tsunami wave in a deep ocean, modulation due to currents is on the order of the ratio of the speed of the surface currents due to the tsunami $(\sim 1 \mathrm{~cm} / \mathrm{s})$ to the group speed of the tsunami $(\sim 200 \mathrm{~m} / \mathrm{s})$ and is negligible (Godin, 2003, 2004). Tsunami-induced variations in ocean surface roughness away from the shore result from variations in wind velocity, which accompany tsunami waves and are theoretically predicted to be much larger than the currents in the tsunami wave (Godin, 2003, 2004, 2005). Godin (2003, 2004,2005 ) investigated interaction of a tsunami wave with turbulent wind under various parameterizations for Reynolds stresses. It was found that significant variations in the mean (over an ensemble of turbulence realizations) wind velocity stem from generation of viscous waves in the atmosphere by large scale, coherent motion of the ocean surface in a tsunami wave. The magnitude of surface roughness modulations and the position of areas with increased and decreased roughness relative to the maxima and minima of sea surface elevations are sensitive to the choice of a closure hypothesis for turbulence in the atmospheric boundary layer. Conversely, measurements of tsunami-induced surface roughness variations can provide crucially important insights into the physics of the interaction of fast surface waves with turbulent wind, which are difficult to obtain by other means.

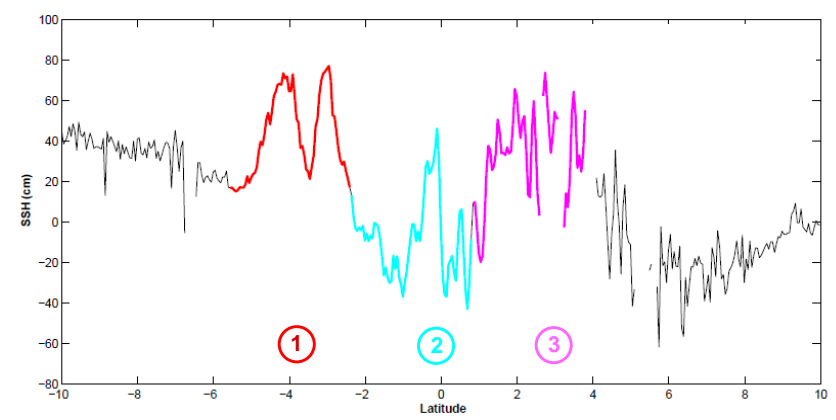

Fig. 4. Sea surface height data from Jason-1 ascending path 129 for cycle 109. Data segments 1, 2, and 3 chosen for detailed analysis of tsunami manifestations are shown in color. Breaks in the graph reflect gaps in the available $\mathrm{SSH}$ data.

At present, there is no universally accepted model of air flow over fast, as compared to the background wind, sea waves. Under assumptions made in (Godin, 2005), in the presence of a monochromatic tsunami wave, the wind speed relative to the ocean surface retains a logarithmic profile up to a few tens of meters above the surface. The effective wind speed depends on the tsunami parameters and, to a first approximation, differs from the background wind speed by the factor

$M=1-\frac{\kappa a c}{H u_{*} \ln \beta}$,

where $\kappa \approx 0.4$ is the von Kármán constant, $u_{*}$ is the friction velocity, $H$ is the height of the background logarithmic boundary layer, $a$ is the sea surface height (SSH) change due to the tsunami, $c$ is tsunami phase speed,

$\beta=\frac{\kappa u_{*} T}{2 \pi z_{0}}$,

$z_{0}$ is the roughness length, and $T$ is the tsunami period. These predictions are illustrated in Fig. 5a assuming that the roughness length is given by Charnock's formula (Charnock, 1955) $z_{0}=0.01 u_{*}^{2} / g$, where $g$ is the acceleration due to gravity. Under this assumption, the background wind speed at a height $10 \mathrm{~m}$ above the sea surface $U_{10} \approx 25 u_{*}$.

In a monochromatic tsunami wave, the effective wind speed varies periodically in time with the SSH change $a$. As long as the relaxation time of wind waves is much smaller than the tsunami period, the time dependence of the effective wind speed can be disregarded when determining statistical characteristics of the sea surface roughness which correspond to a given instant value of the wind modulation $M$. Variations in the radar backscattering strength at nadir, $\sigma_{0}$, resulting from the tsunami-induced wind variations can be found from the Modified Chelton-Wentz algorithm (Witter and Chelton, 1991) or the Freilich-Challenor algorithm (Freilich and Challenor, 1994) by comparing the $\sigma_{0}$ values which correspond to the background and effective wind 

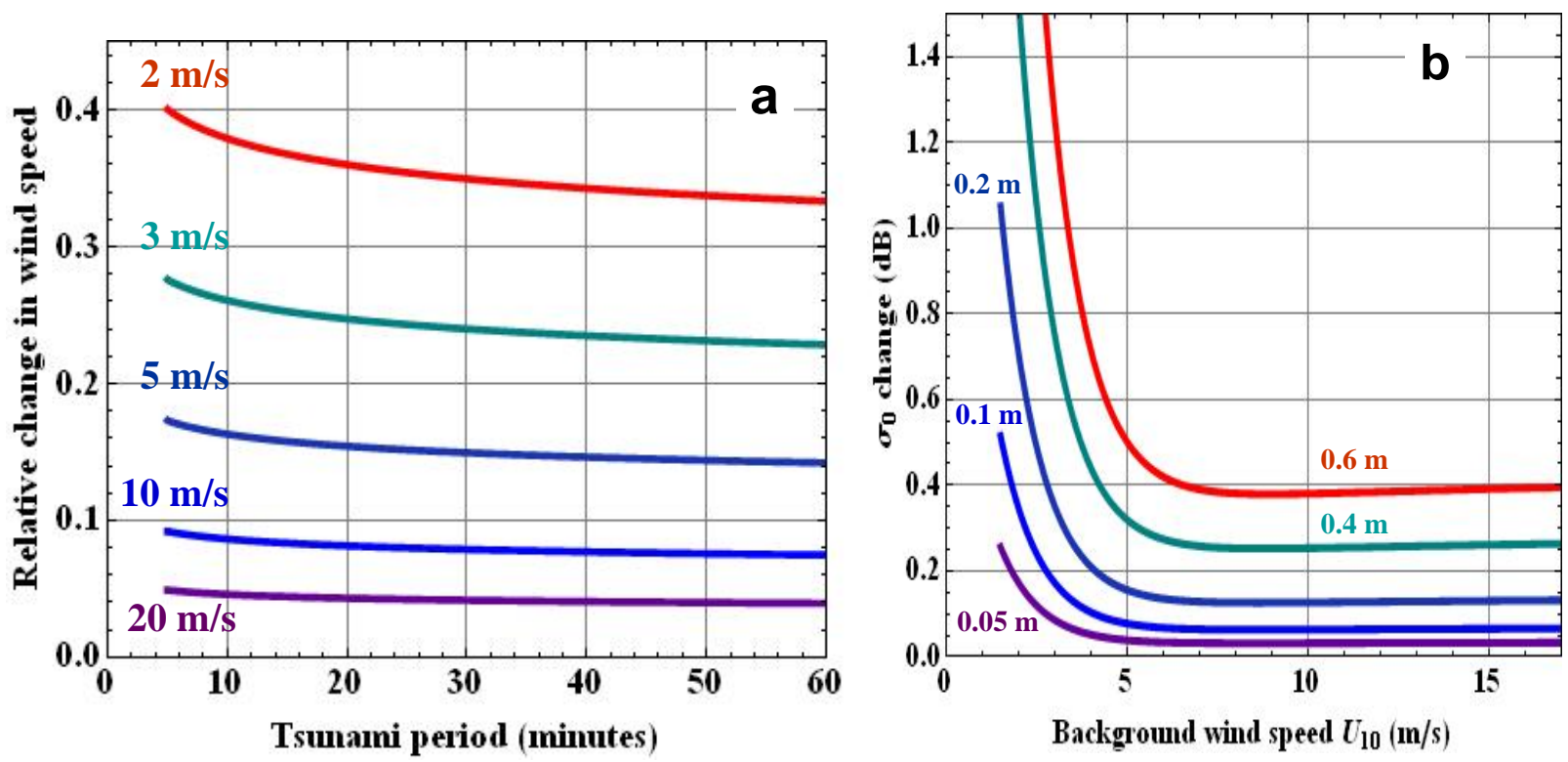

Fig. 5. Theoretically predicted tsunami-induced variations in near-surface wind and radar backscattering strength. (a) Tsunami-induced relative change in wind velocity (Godin, 2005). The relative change $M$ (Eq. 1) in effective wind speed is shown as a function of the tsunami wave period for various values of the background wind speeds from $2 \mathrm{~m} / \mathrm{s}$ to $20 \mathrm{~m} / \mathrm{s}$ at a height $10 \mathrm{~m}$ above the ocean surface. Tsunami amplitude is $0.3 \mathrm{~m}$, thickness of the logarithmic boundary layer $H=60 \mathrm{~m}$, ocean depth is $4000 \mathrm{~m}$. (b) Amplitude of the tsunami-induced variations in the radar backscattering strength $\sigma_{0}$ at nadir. One half of the peak-to-trough $\sigma_{0}$ difference is shown as a function of the background wind speeds at a height $10 \mathrm{~m}$ above the ocean surface for sinusoidal tsunami waves with amplitudes ranging from 0.05 to $0.60 \mathrm{~m}$. Tsunami period is $40 \mathrm{~min}$, thickness of the logarithmic boundary layer $H=60 \mathrm{~m}$, ocean depth is $4000 \mathrm{~m}$.

speeds. With the background wind speeds $U_{10}=2-4 \mathrm{~m} / \mathrm{s}$ at the time of the Jason-1 overflight of the Sumatra-Andaman tsunami leading front, the Modified Chelton-Wentz and Freilich-Challenor algorithms give values between $-2.0 \mathrm{~dB}$ and $-1.7 \mathrm{~dB}$ and between $-3.0 \mathrm{~dB}$ and $-1.7 \mathrm{~dB}$, respectively, for the quantity $N=U_{10} d \sigma_{0} / d U_{10}$. The background wind speed was derived from QuikSCAT satellite measurements made around the time of the tsunami event from the nearest swath about $100 \mathrm{~km}$ from the Jason-1 ground track. Assuming the height of the background logarithmic boundary layer to be $H=50-70 \mathrm{~m}$ (Garratt, 1994), the tsunami period $T=35-45 \mathrm{~min}$ (Gower, 2007), and a maximum and minimum SSH anomaly of $0.6-0.7 \mathrm{~m}$ and $-(0.4-$ $0.5 \mathrm{~m}$ ) due to the tsunami (Ablain et al., 2006), from Eqs. (1) and (2), we obtain values of about $\pm 1 \mathrm{~dB}$ for the maximum and minimum of the radar backscattering strength variation $\Delta \sigma_{0}=N(M-1)$. These estimates are consistent with the Jason-1 observations (Figs. 3b, c) of the tsunami leading front. A detailed comparison of the observed and predicted tsunami-induced $\sigma_{0}$ variations is not possible because of an uncertainty in knowledge of the local meteorological parameters and the tsunami spectrum and the high sensitivity of the tsunami-induced changes in the surface roughness to poorly known environmental parameters, such as the background wind speed. The dependence of the tsunami-induced $\sigma_{0}$ variations on the background wind speed is illustrated in Fig. 5b.
The figure has been produced using the Freilich-Challenor algorithm (Freilich and Challenor, 1994) for radar backscattering strength as a function of the wind speed and Eq. (1) for the modulation of the effective wind speed by a tsunami wave. If the Modified Chelton-Wentz algorithm (Witter and Chelton, 1991) is used instead of the Freilich-Challenor algorithm, the results (not shown) are similar except for prediction of a slow increase of $\Delta \sigma_{0}$ with $U_{10}$ at $U_{10}>8 \mathrm{~m} / \mathrm{s}$. Note a rapid decrease of $\Delta \sigma_{0}$ with the background wind speed at $U_{10}<6 \mathrm{~m} / \mathrm{s}$ in Fig. $5 \mathrm{~b}$. Thus, the combined model of wind perturbation by a tsunami (Godin, 2005) and the radar backscattering at near-nadir directions (Witter and Chelton, 1991; Freilich and Challenor, 1994) indicates that manifestations of tsunami-induced changes in ocean surface roughness are most pronounced in the satellite altimeter $\sigma_{0}$ data at calm to moderate winds and become smaller and insensitive to the background wind speed when $U_{10}>7 \mathrm{~m} / \mathrm{s}$.

Equation (1) and the above estimates suggest that the tsunami-induced changes in ocean surface roughness are detectable but typically small compared to routinely observed changes caused by other geophysical processes, as seen in the $\sigma_{0}$ values measured by Jason-1 (Fig. 2). 

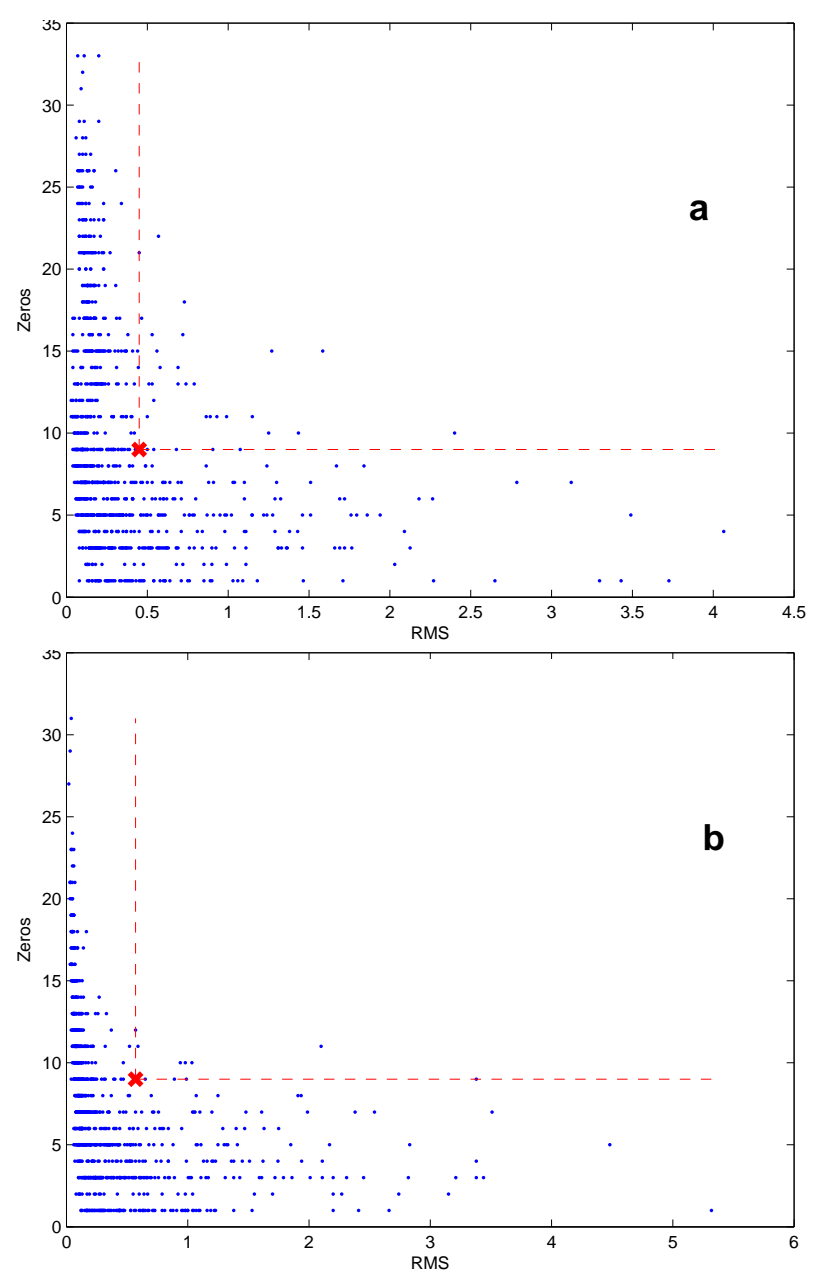

Fig. 6. Randomization tests of the radar backscattering strength data. (a) Ku-band $\sigma_{0}$ data. (b) C-band $\sigma_{0}$ data. The RMS $\sigma_{0}$ anomaly values and the number of zero crossings within a $3.2^{\circ}$ window are calculated for the vicinity of the tsunami leading front (data segment 1 on Fig. 4) and compared to the results from 1000 random windows with midpoints between $20^{\circ} \mathrm{S}$ to $10^{\circ} \mathrm{N}$ along track 129 from Jason-1 cycles 1 through 174. Statistical significance of the hypothesis that surface roughness variations with and without the tsunami are not substantially different is found to be $3.15 \%$ and $0.93 \%$ for $\mathrm{Ku}$ - and C-band measurements, respectively.

\section{Statistical tests of the $\sigma_{0}$ and SSH data}

Ocean surface roughness is influenced by diverse phenomena in the ocean and atmosphere including wind gusts, currents, internal gravity waves, and oceanographic fronts. The resulting $\sigma_{0}$ variability can far exceed the expected tsunami-induced $\sigma_{0}$ variations as evidenced by observations (Fig. 2). Whether the $\sigma_{0}$ variations observed during passage of the Sumatra-Andaman tsunami were indeed caused by the tsunami, and whether tsunami signals can be reliably extracted from $\sigma_{0}$ data, cannot be ascertained without comparing data obtained with and without a tsunami present.
Retrieval of a tsunami signal from "noise" due to other geophysical processes is facilitated by tsunamis having distinctive spatio-temporal characteristics. Regardless of a specific physical mechanism leading to tsunami-induced surface roughness variations, linear interactions result in roughness variations propagating with the tsunami wave fronts and having the same horizontal spatial scales as the surface elevations and the surface currents in the tsunami wave (Godin, 2004). Arguably, the most distinctive attribute of tsunamiinduced roughness variations is their propagation speed relative to the ocean bottom. Unlike sensors in geostationary orbits, satellite altimeters provide a "snapshot" of the ocean surface. The propagation speed criterion cannot be used to identify tsunami-induced features in such data. Instead, we systematically utilize spatial filtering (Powell and Leben, 2004) to suppress $\sigma_{0}$ variations unrelated to the tsunami.

\subsection{Leading front of the tsunami}

Figure 6 shows the results of randomization tests (Edgington, 1995) performed to determine whether $\sigma_{0}$ variations during the Sumatra-Andaman tsunami passage are significantly different from historical Jason-1 measurements accumulated over a nearly 5-year period. (For a detailed description of the method see Appendix A). One thousand 3.2 ${ }^{\circ}$-windows centered between $20^{\circ} \mathrm{S}$ and $10^{\circ} \mathrm{N}$ were randomly selected in the tropical Indian Ocean from cycles 1-174. Mean $\sigma_{0}$ values were subtracted in each window to calculate the $\sigma_{0}$ anomaly. The RMS values and the number of zero crossings were calculated for the $\sigma_{0}$ anomaly in each window and compared to the respective values in the window covering $5.6^{\circ} \mathrm{S}$ to $2.4^{\circ} \mathrm{S}$ along pass 129 in cycle 109 (segment 1 in Fig. 4), which contained the leading front of the SumatraAndaman tsunami. The RMS $\sigma_{0}$ anomaly characterizes the strength of surface roughness variations, while the number of zero crossings serves as a measure of a representative spatial scale of the variations. The randomizations tests show that the tsunami event is atypical in manifesting a considerable $\sigma_{0}$ anomaly of $0.45-0.57 \mathrm{~dB}$ with nine zero crossings within the $3.2^{\circ}$ window. Only a few percent of the randomly selected windows simultaneously have equal or larger values of both the RMS $\sigma_{0}$ anomaly and the number of zero crossings. The statistical significance of the hypothesis that the surface roughness variations with and without the tsunami are not substantially different is rather low: $3.15 \%$ and $0.93 \%$ when estimated using the $\mathrm{Ku}$ - and $\mathrm{C}$-band $\sigma_{0}$ data, respectively.

A more accurate separation of variations having distinct spatial scales is achieved with a spectral approach. In each new $3.2^{\circ}$-window, the $\sigma_{0}$ and SSH data were detrended by removing the best linear fit. Windows with unphysically large SSH variations of more than $150 \mathrm{~cm}$ from the median were excluded from consideration. The Fourier spectrum of the detrended data was normalized to account for the high variability of the high-frequency part of the spectrum. (For a detailed description of the method see Appendix B). Spatial 


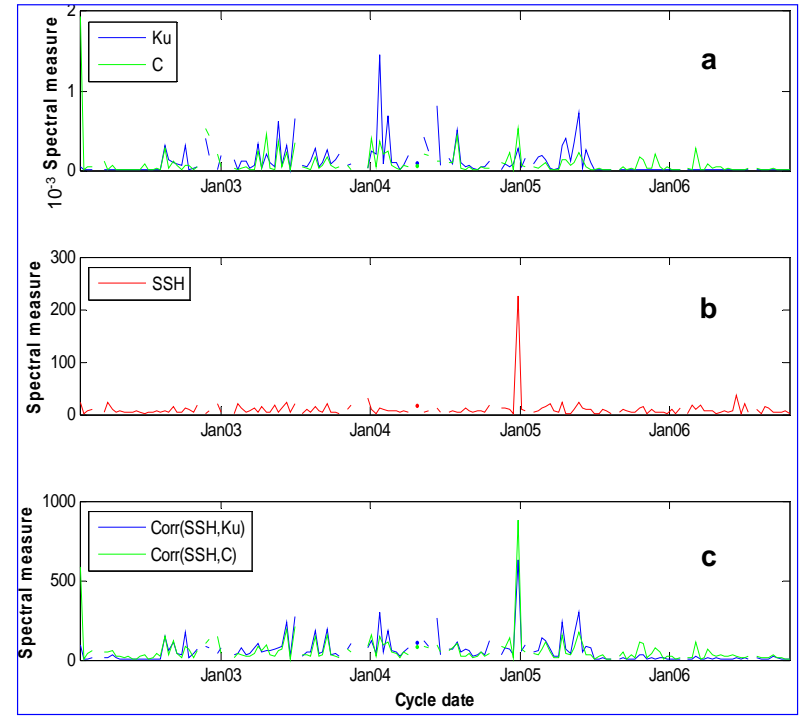

Fig. 7. Spectral measures of radar backscattering strength and sea surface height anomalies observed by Jason-1 and their correlation as observed between $5.6^{\circ} \mathrm{S}$ and $2.4^{\circ} \mathrm{S}$ along track 129 from cycles 1 through 174 . (a) Ku- and C-band backscattering strength anomalies. (b) Sea surface height anomaly. (c) Correlations of the $\mathrm{Ku}$ and C-band backscattering strengths with the sea surface height. The spectral measures are calculated in the range of spatial scales characteristic of the tsunami.

filtering was implemented by summing up the powers of the Fourier components with spatial scales from about $90 \mathrm{~km}$ to $300 \mathrm{~km}$. To quantify the correlation between the $\sigma_{0}$ and $\mathrm{SSH}$ anomalies, the power of the co-spectrum, i.e. the Fourier spectrum of their cross-correlation function, was calculated in the range of spatial scales from about $90 \mathrm{~km}$ to $300 \mathrm{~km}$. The data processing algorithm was applied to windows covering $5.6^{\circ} \mathrm{S}$ to $2.4^{\circ} \mathrm{S}$ along pass 129 in Jason-1 cycles $1-174$ (Fig. 7). As expected, SSH data give the highest peak during the tsunami passage (cycle 109). In each of the $\mathrm{Ku}$ and $\mathrm{C}$ bands, the power of $\sigma_{0}$ variations also peaks at this cycle, although it has higher peaks at a few other cycles. The tsunami event is unique in providing a very strong peak in the correlation between spatially filtered SSH and $\sigma_{0}$ data obtained in both the $\mathrm{Ku}$ - and $\mathrm{C}$-bands (Fig. 7).

Randomization tests (Fig. 8) were performed by randomly selecting $9993.2^{\circ}$-windows centered between $38^{\circ} \mathrm{S}$ to $8^{\circ} \mathrm{N}$ in the Indian Ocean from Jason-1 cycles 1-174. (For a detailed description of the method see Appendices A and B.) The tsunami event and windows meeting the excessive SSH variability criterion were excluded from the set. The number of independent random windows within the chosen geographic area is limited by the number of Jason-1 cycles recorded since the satellite launch. The set of random windows was used to evaluate probability distributions of parameters characterizing radar backscattering strength from
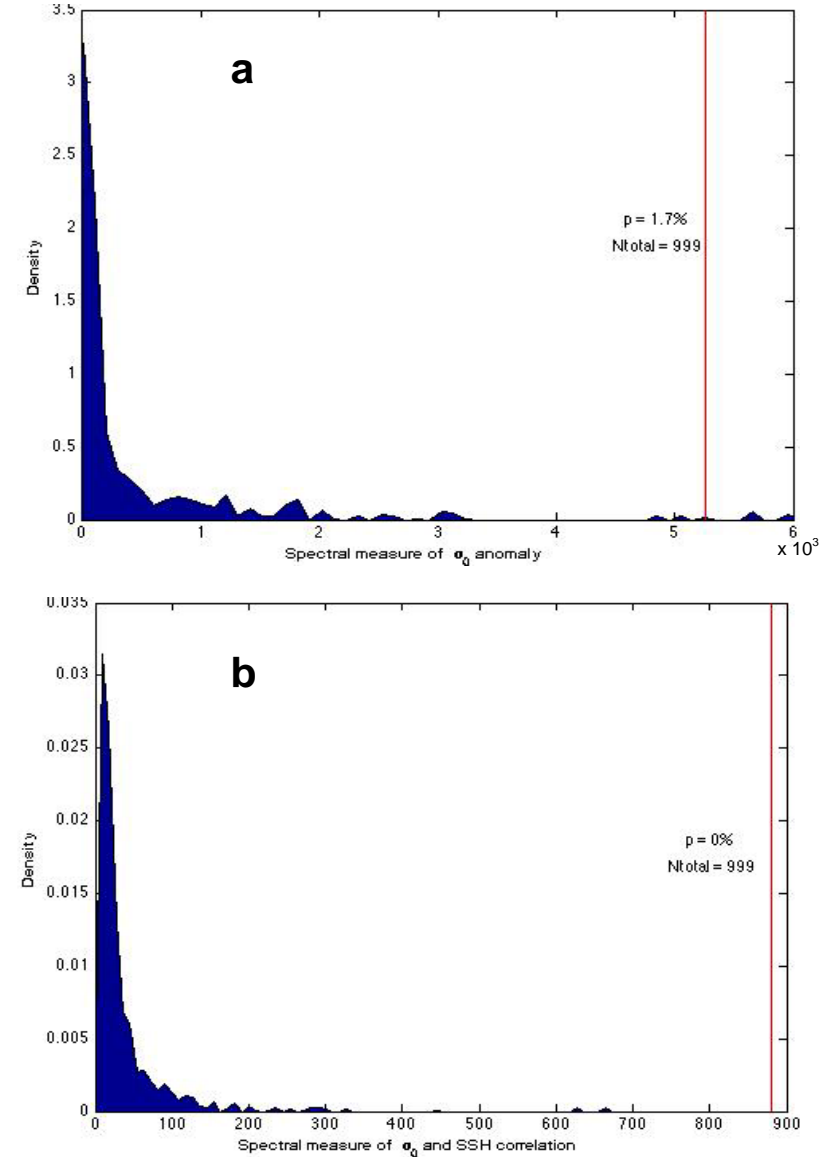

Fig. 8. Randomization tests of spectral measures of radar backscattering strength anomaly and its correlation with sea surface height anomaly as observed by Jason- 1 in the vicinity of the tsunami leading front. (a) Randomization tests of the spatially filtered C-band $\sigma_{0}$ anomaly. (b) Randomization tests of the co-spectrum of the spatially filtered C-band $\sigma_{0}$ and sea surface height anomalies. The anomaly and the co-spectrum are calculated for the tsunami event (red line) as observed between $5.6^{\circ} \mathrm{S}$ and $2.4^{\circ} \mathrm{S}$ along track 129 for Jason-1 cycle 109 and compared to the results from $9993.2^{\circ}$ random windows. Statistical significance of the hypotheses that the correlation between spatially filtered surface roughness variations and sea surface height anomaly with and without the tsunami are not substantially different is found to be less than $0.1 \%$.

the ocean surface. The probability distributions densities of the spatially filtered $\sigma_{0}$ anomaly, as measured in $\mathrm{C}$ band, (Fig. 8a) and the $\sigma_{0}-\mathrm{SSH}$ correlation (Fig. 8b) show that the $\sigma_{0}$ variability equalled or exceeded its level in the tsunami event in $1.7 \%$ of cases, while the correlation level in the tsunami event was uniquely large. For the $\sigma_{0}$ data obtained in Ku band (not shown), the corresponding figure is $6.8 \%$ for the $\sigma_{0}$ variability; the $\sigma_{0}-\mathrm{SSH}$ correlation remains uniquely large in the tsunami event. Thus, the randomization tests provide very strong evidence that the $\sigma_{0}$ variations and, hence, underlying surface roughness variations observed by Jason-1 

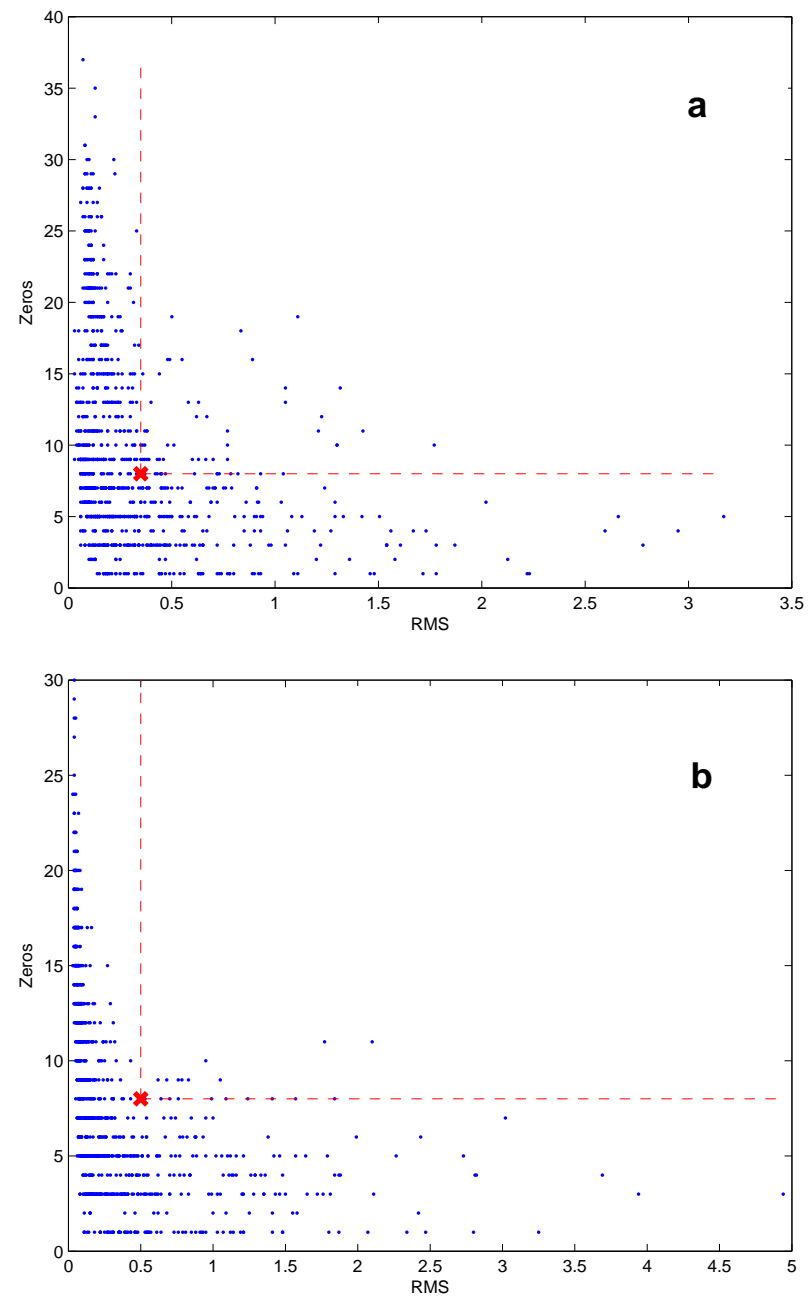

Fig. 9. Randomization tests of the radar backscattering strength data obtained away from the tsunami leading front. (a) Ku-band $\sigma_{0}$ data. (b) C-band $\sigma_{0}$ data. The RMS $\sigma_{0}$ anomaly values and the number of zero crossings within the window between $0.8^{\circ} \mathrm{N}$ and $4.0^{\circ} \mathrm{N}$ (data segment 3 on Fig. 4) are compared to the results from $10003.2^{\circ}$ random windows with midpoints between $20^{\circ} \mathrm{S}$ to $10^{\circ} \mathrm{N}$ along track 129 from Jason- 1 cycles 1 through 174. Statistical significance of the hypothesis that surface roughness variations with and without the tsunami are not substantially different is found to be $6.43 \%$ and $2.16 \%$ for $\mathrm{Ku}-$ and C-band measurements, respectively.

during the Sumatra-Andaman tsunami passage were indeed caused by the tsunami.

\subsection{Observations away from the tsunami leading front}

The same data processing techniques were applied to $3.2^{\circ}$ non-overlapping windows, which extend from the segment 1 in Fig. 4 to the south and to the north along the Jason-1 path 129 for cycle 109. The windows which contained data gaps too extensive to apply a particular technique had to be excluded from consideration.
Radar backscattering strength in windows 2 and 3, where the tsunami is unambiguously present in SSH records and has significant amplitude (Fig. 4), were found to be atypical as compared to the data obtained on the other Jason-1 cycles. In the window 2 , the $\mathrm{Ku}$ - and $\mathrm{C}$-band $\sigma_{0}$ anomalies have $3-4$ zero crossings and considerable RMS amplitude of $0.48-0.66 \mathrm{~dB}$. Only $9.1 \%$ and $9.7 \%$ percent of the randomly selected windows simultaneously have equal or larger values of both the RMS $\sigma_{0}$ anomaly and the number of zero crossings in the $\mathrm{Ku}$ - and $\mathrm{C}$-bands, respectively. In the window 3 (Fig. 9), the $\mathrm{Ku}$ - and $\mathrm{C}$-band $\sigma_{0}$ anomalies have eight zero crossings in both $\mathrm{Ku}$ - and C-bands and considerable RMS amplitude of $0.35-0.50 \mathrm{~dB}$. Among the randomly selected windows, only $6.4 \%$ and $2.2 \%$ simultaneously have equal or larger values of both the RMS $\sigma_{0}$ anomaly and the number of zero crossings in the $\mathrm{Ku}$ - and $\mathrm{C}$-bands, respectively. On the other hand, radar backscattering strength anomaly in the windows to the south of $5.6^{\circ} \mathrm{S}$, where the tsunami wave had not arrived by the time of the Jason-1 overflight, does not appear substantially different from that in the randomly selected windows with respect to the criterion of simultaneously having a large number of zero crossings and a large RMS magnitude.

Figure 10 presents results of application of the spectral approach. In both $\mathrm{Ku}$ - and $\mathrm{C}$-bands, the spectral measure of cross-correlation between sea surface height and radar backscattering strength is small in the windows which lie to the south of $5.6^{\circ} \mathrm{S}$ (Fig. 10a). The spectral measure of the cross-correlation increases sharply when the tsunami arrives and returns to small values after passage of the bulk of the tsunami energy (Figs. 4 and 10a). Data gaps did not allow spectral processing of the radar backscattering strength in the window 3 (Fig. 4) as well as in two other windows between approximately $18.4^{\circ} \mathrm{S}-15.2^{\circ} \mathrm{S}$ and $4.0^{\circ} \mathrm{N}-7.2^{\circ} \mathrm{N}$. The spectral measure of the radar backscattering strength (not shown) in the six windows to the south of $5.6^{\circ} \mathrm{S}$ is close to median values in the probability distribution evaluated from one thousand random windows. For window 2 (Fig. 4), the spectral measure of the radar backscattering strength is larger than in $96.4 \%$ or $97.8 \%$ of the random windows in the $\mathrm{C}$ - and $\mathrm{Ku}$-band, respectively. Randomization tests show that the values of the $\sigma_{0}-\mathrm{SSH}$ cross-correlation on the Jason-1 path 129 for cycle 109 remain rather typical for the windows which lie to the south of $5.6^{\circ} \mathrm{S}$. On the other hand, in the window 2 the correlation values in both $\mathrm{Ku}$ - and $\mathrm{C}$-bands are far larger than in any of 1000 randomly selected windows. These values exceed even the correlation values in the window 1 (Fig. 4), which contains the leading front of the tsunami (Fig. 10b, c).

These additional randomization tests strongly reinforce the evidence of exceptional features in the radar backscattering strength in the presence of a tsunami, which was obtained in Sect. 4.1 from data in the vicinity of the leading front of the Sumatra-Andaman tsunami. Moreover, the results demonstrate that our data processing algorithms, without any 

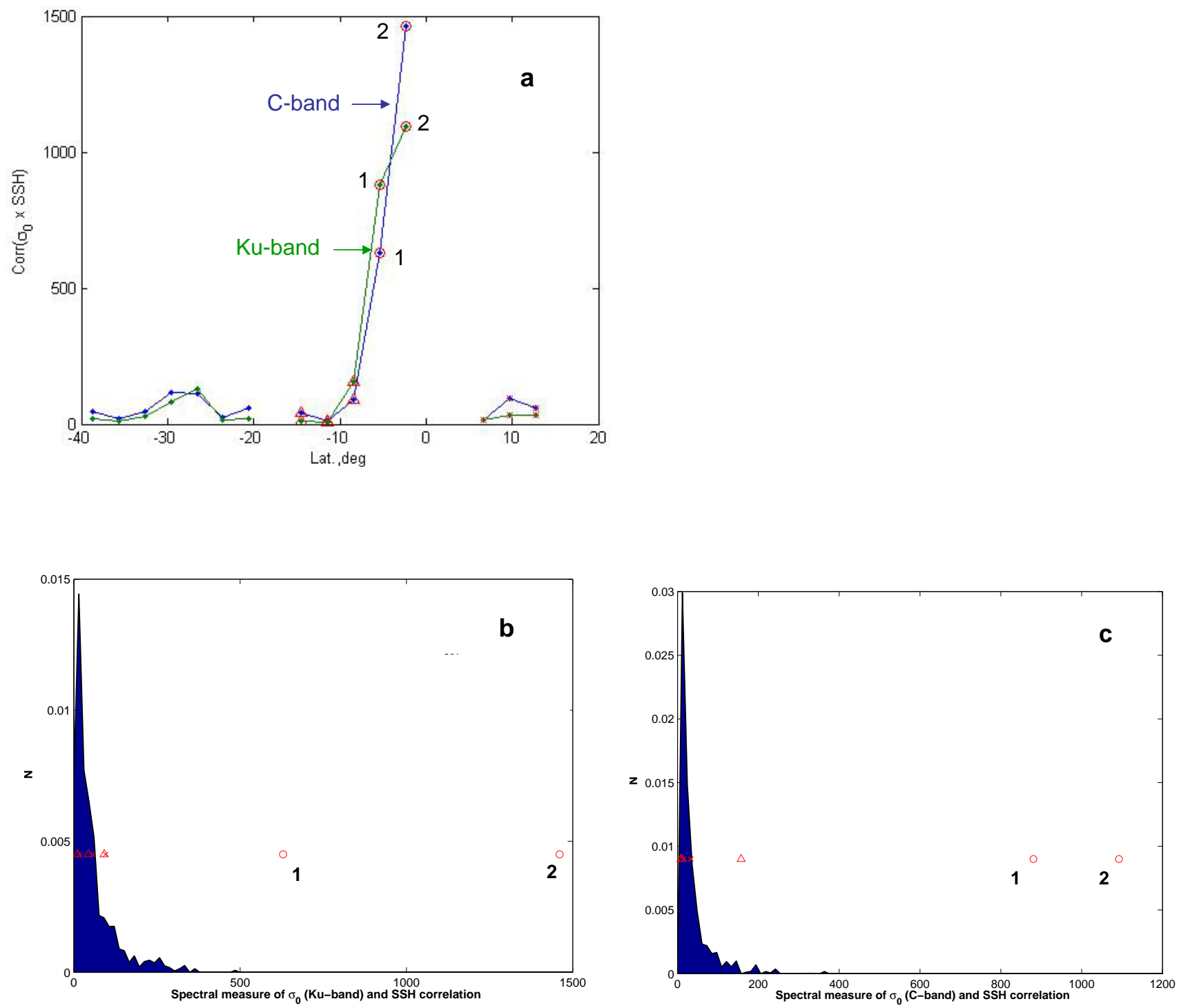

Fig. 10. Cross-correlation between spatially filtered radar backscattering strength and sea surface height anomalies. (a) Co-spectra of SSH and $\sigma_{0}$ measured in either $\mathrm{Ku}$ - or C-band for consecutive 3.2 $2^{\circ}$ windows along track 129 for Jason-1 cycle 109 as a function of latitude of the southern end of the window. Breaks in graphs reflect gaps in the available SSH and/or $\sigma_{0}$ data. (b) Randomization tests of the co-spectrum of the spatially filtered Ku-band $\sigma_{0}$ and sea surface height anomalies. (c) Same as in panel $b$ for the co-spectrum of the spatially filtered C-band $\sigma_{0}$ and sea surface height anomalies. Results for $3.2^{\circ}$ windows along track 129 for cycle 109 are shown by symbols: triangles for windows to the south of $5.6^{\circ} \mathrm{S}$, X's for windows to the north of $7.2^{\circ} \mathrm{N}$, and circles for the windows 1 and 2 in Fig. 4.

modifications or "tuning", allow detection of tsunami manifestations in the radar backscattering strength for various tsunami waveforms and can successfully discriminate between regions where the tsunami is and is not present. Detection of tsunami manifestations in the Jason- $1 \sigma_{0}$ records on path 129 for cycle 109 was simplified by the extraordinary strength of the Sumatra-Andaman tsunami.

\section{Discussion}

Satellite altimeters afford a unique opportunity to study the effects of a tsunami wave on the ocean surface through concurrent measurements of the surface height and the radar backscattering strength. Availability of the surface height data allows one to compare statistical properties of the radar backscattering strength when there is and there is no tsunami wave present, without employing tsunami source and propagation models. Using observations of the Sumatra-Andaman tsunami from the Jason-1 satellite, we have demonstrated 
experimentally for the first time that tsunamis in the open ocean cause distinct, measurable changes in ocean surface roughness.

The same conclusion has been reached from statistical analyses of several different attributes of the radar backscattering data: (I) magnitude of the radar backscattering strength anomaly and its representative spatial scale, as given by the number of zero crossings in a data segment of a fixed spatial extent; (II) magnitude of the radar backscattering strength anomaly filtered to the range of spatial scales representative of a tsunami wave; and (III) correlation of the radar backscattering strength and the sea surface height anomalies filtered to the range of spatial scales representative of a tsunami wave. One or another form of spatial filtering is necessary to distinguish a tsunami signal from potentially stronger variations induced by other geophysical processes with different spatial scales. The strongest evidence of tsunami manifestations in ocean surface roughness comes from the correlation of the $\sigma_{0}$ and SSH variations. Given the size of the set of random windows utilized in our analysis, uniquely high values of the correlation during the tsunami event translate into a statistical confidence of better than $99.9 \%$ of the conclusion that tsunamis in deep water are accompanied by substantial changes in ocean surface roughness away from shore. With the $\sigma_{0}$ data alone, the statistical confidence is not as high but is still better than $98 \%$. These results are in agreement with theoretical predictions (Godin, $2003,2004,2005$ ) and provide important insights into the physics of wave-wind interaction. The robustness of the statistical analysis has been demonstrated by applying the same data processing techniques to different data segments with and without the tsunami present.

While our research establishes unambiguously existence of significant tsunami-induced variations in sea surface roughness, the critically important practical issues of optimal retrieval of a tsunami signal from various measures of sea surface roughness and of potential applications of these measures to tsunami detection and characterization are beyond the scope of this paper. Our analysis relied on satellite altimeter data records. Use of the radar backscattering strength component of these records would be of little use for tsunami detection and early warning purposes because of a limited number of operational satellite altimeters and availability of the collocated sea surface height data, which are easier to interpret. However, the tsunami-induced surface roughness variations are likely to be observable with other types of space- and airborne sensors. Unlike the sea surface height, which is measured at nadir points along the satellite ground track, tsunami-induced variations in sea surface roughness can be potentially measured over wider swaths with spaceborne and airborne side-looking radars and scanning microwave radiometers. Instead of a correlation between surface elevation and radar backscattering strength, spatial averaging of radar backscattering strength or brightness temperature along hypothetical tsunami wave fronts would be used with these kinds of sensors to distinguish any tsunami signal from noise due to other sources of the roughness change. The much broader surface coverage of these sensors suggests that they are more promising for early tsunami detection than satellite altimeters and may be an important element in a future global system for tsunami detection and warning. Further research is required to demonstrate tsunami detection with side-looking radars and scanning microwave radiometers. We anticipate our study to be a starting point for development of advanced data processing algorithms and satellite- and airborne microwave sensors for identification of tsunami-induced surface roughness changes to enhance existing regional tsunami detection and early warning systems and contribute to a future global system.

\section{Appendix A}

\section{Randomization tests}

A randomization test is a permutation test based on randomization (random assignment) to test a null hypothesis about the outcome of an experiment or observation under investigation (Edgington, 1995). The significance level of such a test can be interpreted in the same way as for conventional statistical tests: if it is less than $5 \%$ there is some evidence that the null hypothesis is not true; if it is less than $1 \%$ it provides strong evidence that the null hypothesis is not true; and if it is less that $0.1 \%$ it provides very strong evidence that the null hypothesis is not true (Manly, 1997). Scientific hypotheses of interest are evaluated as alternatives to the null hypothesis of randomness. In this study, the null hypothesis is that the surface roughness variation associated with the tsunami is not significantly different from the ocean surface roughness variations typically observed. Several randomization tests were performed to test this hypothesis using the radar backscattering strength at nadir $\left(\sigma_{0}\right)$, measured by the Jason-1 microwave altimeter instrument in $\mathrm{Ku}$ - and $\mathrm{C}$-bands (Figs. 6 and 8-10). Random windows were chosen independently for each test.

In the randomization tests, data metrics were calculated in data segments containing 65 (including both endpoints) 1$\mathrm{Hz}$ subsatellite points in the Jason-1 geophysical data record, which gives a window width of approximately $3.2^{\circ}$. No attempt was made to optimize the window width. Qualitatively, results appear to be insensitive to the width as long as windows contain $\mathrm{O}\left(10^{2}\right)$ data points. The first statistical metric evaluated was the root mean square (RMS) anomaly. A total of 1000 trials were performed for the Jason-1 Ku- and C-band RMS $\sigma_{0}$ anomaly values to test the null hypothesis. Significance levels of $17 \%$ and $15 \%$ were found for the $\mathrm{Ku}-$ and C-band $\sigma_{0}$ anomalies, respectively, which are not significant. This null result based on RMS backscattering strength anomaly, however, is attributed to the lack of spatial scale differentiation in the RMS statistics. A considerable number 
of outcomes (about 3\%) had high RMS $\sigma_{0}$ values, but only exhibited a linear trend over the data windows. SSH records and the physical considerations outlined in Sect. 3 indicate that tsunami-related $\sigma_{0}$ anomalies should change sign within a $3.2^{\circ}$-window at least several times.

A second statistical metric, zero crossings, was computed with the RMS $\sigma_{0}$ anomaly statistic to perform a twoparameter randomization test to evaluate both the spatial scale and the magnitude of $\sigma_{0}$ anomaly. The results of the two-parameter randomization tests for $\mathrm{Ku}$ - and $\mathrm{C}$ - band $\sigma_{0}$ anomalies in the data segment 1 (Fig. 4) are shown in Fig. 6. Both the $\mathrm{Ku}$ - and $\mathrm{C}$-band tests were significant at the $5 \%$ level. The C-band test reached the $1 \%$ level, which is good evidence that the null hypothesis is not true.

To analyze and represent the results of the singleparameter randomization tests shown in Figs. 8 and 10b, c, we used a kernel smoothing process. The aim of kernel smoothing is to non-parametrically estimate a probability density function. In contrast to a histogram, kernel smoothing provides a smooth-curve estimation to the probability density function. The kernel smoothing process replaces the histogram "box" as the basic building block with a kernel function. Several different kernels exist, each with varying levels of efficiency (Wand and Jones, 1995). One of the most common choices of kernel function, and indeed the one used in this study, is the normal or Gaussian kernel. The use of this kernel is particularly desirable largely due to the ease of calculation of the optimal bandwidth (Wand and Jones, 1995). There are several ways to determine the optimal bandwidth for the kernel smoothing process. The method used to calculate the bandwidth in this study is based on the Generalized Cross Entropy estimator presented by Botev (2006).

\section{Appendix B}

\section{Spectral approach to radar backscattering strength and sea surface height data processing}

Satellite altimeter measurements of sea surface height and roughness are intrinsically noisy because the processes of microwave propagation in the atmosphere and scattering from the sea surface do not allow a deterministic description and lead to strong fluctuations in the amplitude and phase of the backscattered signal. The magnitude of geophysically relevant signals in the measured microwave time of flight and $\sigma_{0}$ are comparable to fluctuations of these quantities. Retrieval of tsunami-related information from the satellite altimeter data is further complicated by the effects of other geophysical processes which can overshadow the tsunami signal, especially its effect on surface roughness. Some of the interfering processes have spatial extent larger than a tsunami wavelength while others have correlation length that is much smaller than a tsunami wavelength. We have developed a spectral data processing algorithm to suppress the noise and retrieve a signal due to a tsunami, if there is any, by using a range of possible tsunami spatial scales as the only a priori information. The algorithm is designed for processing satellite altimeter data in segments of equal length on the order of several hundred $\mathrm{km}$, which contain SSH and $\sigma_{0}$ measurements at $\mathrm{O}\left(10^{2}\right)$ discrete points. The algorithm was applied to approximately $3.2^{\circ}$ windows of the Jason- 1 data. Each window contains 64 data points as obtained from the Jason-1 geophysical data records.

The initial stage of data processing consists of detrending the data in each window by removing the best linear fit in order to suppress the effects of variations with scales larger than the window length. The SSH and $\sigma_{0}$ data with the trends removed are referred to as the SSH and $\sigma_{0}$ anomalies. Occasionally, the SSH anomaly takes unphysically large values. Data segments with absolute value of the SSH anomaly exceeding $150 \mathrm{~cm}$ were excluded from consideration.

The next step includes multiplication of each 64-point data segment by a window function, formed by a combination of two error functions with smoothly decreasing wings. The window function eliminates the difference between data values at the segment end points, while leaving intact about $90 \%$ of data. This step suppresses artificial high-frequency noise in the signal spectrum as well as sensitivity to data segment selection.

Power spectra were found as squared absolute values of the discrete Fourier transform of the windowed signal anomalies: $S_{\sigma}(K)=\mid$ FFT $\left.\left[\sigma_{0}\right]\right|^{2}, S_{\mathrm{SSH}}(K)=|\mathrm{FFT}[\mathrm{SSH}]|^{2}, \quad$ while the correlation between the two signals was characterized by the absolute value of the co-spectrum: $C(K)=\left|\mathrm{FFT}\left[\sigma_{0}\right] \cdot \mathrm{FFT}^{*}[\mathrm{SSH}]\right|$. Here, the asterisk denotes complex conjugation. Correlation between the SSH and $\sigma_{0}$ anomalies was considered as a proxy for a causal relationship between a tsunami wave and spatially filtered $\sigma_{0}$ variations.

It was found that the spectra $S_{\sigma}(K)$ and $S_{\mathrm{SSH}}(K)$ display very high variability of several orders of magnitude at large wave numbers $K$ (i.e. at small spatial scales) (Fig. B1a). One reason for this variability lies in the nature of microwave backscattering at nadir, which exhibits very strong and abrupt variations at light wind conditions due to the appearance and disappearance of specular points on the sea surface and interference between reflections from distinct specular points. To account for the high $\sigma_{0}$ variability at light winds, the Fourier spectra of the anomaly were normalized (Fig. B1b) by their root mean square value in the high-frequency band $\left(21 / 32 k_{\max }, k_{\max }\right)$, where $k_{\max }$ is the maximum wave number in the Fourier spectrum. The normalized spectra were averaged over the low-frequency band $\left(3 / 32 k_{\max }, 5 / 16 k_{\max }\right)$ (Fig. B1b). We refer to the resulting value as the spectral measure of the respective signal (spatially filtered SSH and $\sigma_{0}$ anomalies or their correlation). Effectively, for any signal such processing quantifies the contrast between the energy of the spectral components with large spatial scales 

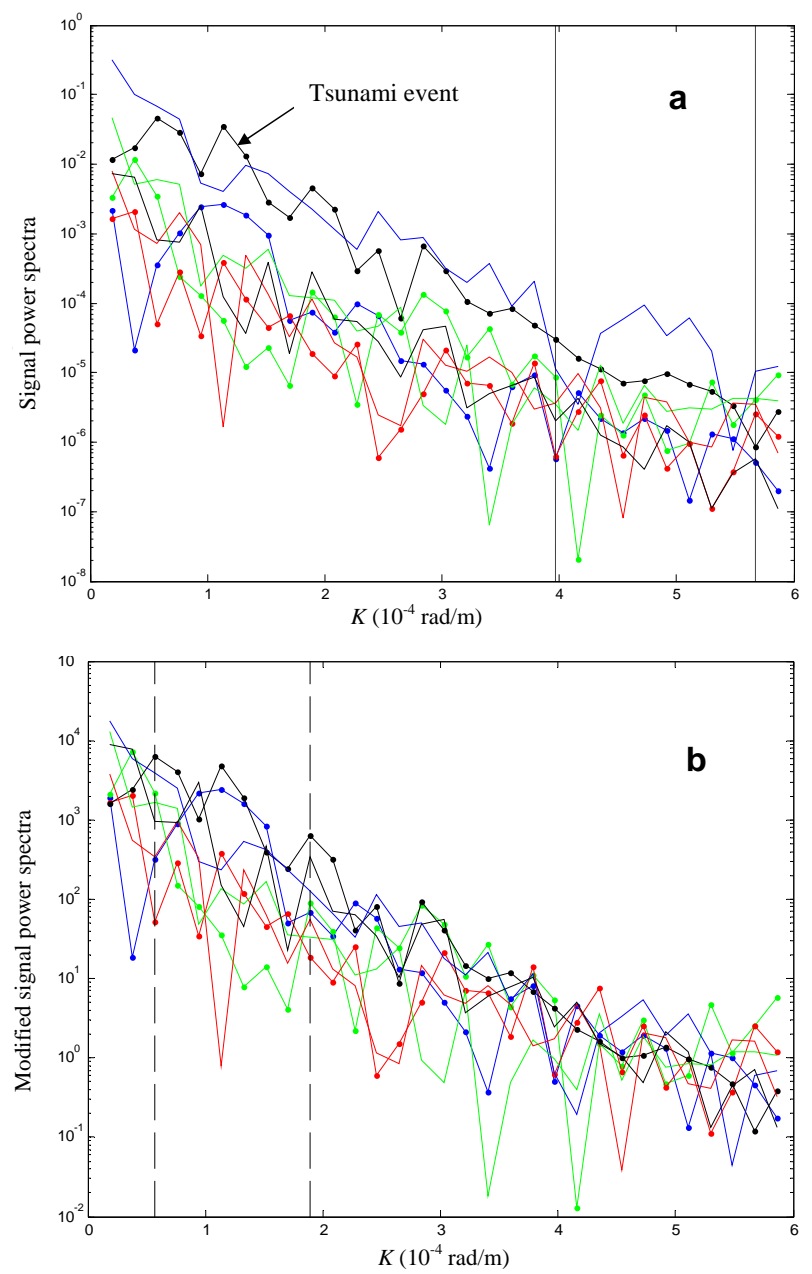

Fig. B1. Power spectra of the $\sigma_{0}$ anomaly. (a) Seven randomly chosen examples of the anomaly power spectra and the spectrum in the tsunami event (black line with dots). Vertical dashed lines show the high-frequency band used for spectra normalization. (b) Same spectra after normalization. Vertical dashed lines show the spatial frequency band where tsunami manifestations are expected to be pronounced.

representative of a tsunami wave and at small scales unrelated to the tsunami. Figure $7 \mathrm{~b}$ demonstrates the filtering efficiency of the proposed data processing algorithm.

Acknowledgements. This work was supported, in part, by the US Navy under STTR contract N06-T002 and by NASA Ocean Surface Topography Mission Science Team grants NNX08AR60G and NNX08AR48G. The authors thank P. J. Cefola, S. F. Clifford (deceased), E. A. Godin, S. F. Dotsenko, A. J. Gasiewski, D. L. Jackson, E. W. Leuliette, R. S. Nerem, D. R. Palmer, S. V. Stanichny, V. V. Titov, Y. I. Troitskaya, and D. A. Walker for discussions.

Edited by: S. Tinti

Reviewed by: S. Tinti and another anonymous referee

\section{References}

Ablain, M., Dorandeu, J., Le Traon, P.-Y., and Sladen A.: High resolution altimetry reveals new characteristics of the December 2004 Indian Ocean tsunami, Geophys. Res. Lett., 33, L21602, doi:10.1029/2006GL027533, 2006.

Behrens, J., Androsov, A., Harig, S., Klaschka, F., Mentrup, L., Pranowo, W. S., Cui, H. Y., Schröter, J., and Hiller, W.: Design and performance testing of a multi-sensor quick assimilation technique for tsunami early warning in the GITEWS simulation system, Geophys. Res. Abstr., 10, EGU2008-A-01878, 2008.

Bernard, E. N., Mofjeld, H. O., Titov, V., Synolakis, C. E., and González, F. I.: Tsunami: scientific frontiers, mitigation, forecasting and policy implications, Phil. T. R. Soc. A, 364, 19892007, doi:10.1098/rsta.2006.1809, 2006.

Botev, Z. I.: A novel nonparametric density estimator, in: Postgraduate Seminar Series, Mathematics, The University of Queensland, St. Lucia, 1-7, 2006.

Charnock, H.: Wind stress on a water surface, Q. J. Roy. Meteor. Soc., 81, 639-640, 1955.

Cohen, J. E. and Belcher, S. E.: Turbulent shear flow over fastmoving waves, J. Fluid Mech., 386, 345-371, 1999.

Dudley, W. C. and Lee, M.: Tsunami!, University of Hawaii Press, Honolulu, 5 pp., 302-303, 321-322, 1998.

Edgington, E. S.: Randomization Tests, Marcel Dekker, New York, 1995.

Fine, I. V., Rabinovich, A. B., and Thomson, R. E.: The dual source region for the 2004 Sumatra tsunami, Geophys. Res. Lett., 32, L16602, doi:10.1029/2005GL023521, 2005.

Freilich, M. H. and Challenor, P. G.: A new approach for determining fully empirical altimeter wind speed model functions, J. Geophys. Res., 99, 25051-25062, 1994.

Fu, L.-L. and Cazenave, A.: Satellite Altimetry and Earth Sciences: A Handbook of Techniques and Applications, Academic Press, San Diego, 95-99, 453-456, 2001.

Fujii, Y. and Satake, K.: Tsunami source of the 2004 SumatraAndaman earthquake inferred from tide gauge and satellite data, B. Seismol. Soc. Am., 97, 192-207, doi:10.1785/0120050613, 2007.

Garratt, J. R.: The Atmospheric Boundary Layer, Cambridge University Press, Cambridge, 1994.

Geist, E. L., Titov, V. V., Arcas, D., Pollitz, F. F., and Bilek, S. L.: Implications of the 26 December 2004 Sumatra-Andaman earthquake on tsunami forecast and assessment models for great subduction-zone earthquakes, B. Seismol. Soc. Am., 97, 249270, doi:10.1785/0120050619, 2007.

Godin, O. A.: Influence of long gravity waves on wind velocity in the near-water layer and feasibility of early tsunami detection, Dokl. Earth Sci., 391, 841-844, 2003.

Godin, O. A.: Air-sea interaction and feasibility of tsunami detection in the open ocean, J. Geophys. Res., 109, C05002, doi:10.1029/2003JC002030, 2004.

Godin, O. A.: Wind over fast waves and feasibility of early tsunami detection from space, in: Frontiers of Nonlinear Physics, edited by: Litvak, A., Inst. Appl. Phys., Nizhny Novgorod, 210-215, 2005.

Godin, O. A. and Irisov, V. G.: A perturbation model of radiometric manifestations of oceanic currents, Radio Sci., 38, 8070, doi:10.1029/2002RS002642, 2003.

González, F. I., Bernard, E. N., Meinig, C., Eble, M. C., Mofjeld, 
H. O., and Stalin, S.: The NTHMP tsunameter network, Nat. Hazards, 35, 25-39, doi: 10.1007/s11069-004-2402-4, 2005.

Gower, J.: The 26 December 2004 tsunami measured by satellite altimetry, Int. J. Remote Sens., 28, 2897-2913, doi:10.1080/01431160601094484, 2007.

Hara, T. and Plant, W. J.: Hydrodynamic modulation of short wind-wave spectra by long waves and its measurement using microwave backscatter, J. Geophys. Res., 99, 9767-9784, 1994.

Hayashi, Y.: Extracting the 2004 Indian Ocean tsunami signals from sea surface height data observed by satellite altimetry, J. Geophys. Res., 113, C01001, doi:10.1029/2007JC004177, 2008.

Hirata, K., Satake, K., Tanioka, Y., Kuragano, T., Hasegawa, Y., Hayashi, Y., and Hamada, N.: The 2004 Indian Ocean tsunami: Tsunami source model from satellite altimetry, Earth Planets Space, 58, 195-201, 2006.

Hoechner, A., Babeyko, A. Y., and Sobolev, S. V.: Enhanced GPS inversion technique applied to the 2004 Sumatra earthquake and tsunami, Geophys. Res. Lett., 35, L08310, doi:10.1029/2007GL033133, 2008.

Kudryavtsev, V. N., Mastenbroek, C., and Makin, V. K.: Modulation of wind ripples by long surface waves via the air flow: a feedback mechanism, Bound.-Lay. Meteorol., 83, 99-116, 1997.

Kulikov, E. A., Medvedev, P. P., and Lappo, S. S.: Satellite recording of the Indian Ocean tsunami on December 26, 2004, Dokl. Earth Sci., 401A, 444-448, 2005.

Kumar, B. P., Kumar, R. R., Dube, S. K., Murty, T., Gangopadhyay, A., Chaudhuri, A., and Rao A. D.: Tsunami travel time computation and skill assessment for the 26 December 2004 event in the Indian Ocean, Coast. Eng. J., 48, 147-166, 2006.

Lay, T., Kanamori, H., Ammon, C. J., Nettles, M., Ward, S. N., Aster, R. C., Beck, S. L., Bilek, S. L., Brudzinski, M. R., Butler, R., DeShon, H. R., Ekström, G., Satake, K., and Sipkin, S.: The Great Sumatra-Andaman Earthquake of 26 December 2004, Science, 308, 1127-1133, doi:10.1126/science.1112250, 2005.

Lautenbacher, C. C.: Tsunami warning systems, The Bridge, 35, 21-25, 2005.

Levin, B. W. and Nosov, M. A.: Physics of Tsunamis and Kindred Phenomena, Janus-K, Moscow, 2005.

Manly, B. F. J.: Randomization, Bootstrap and Monte Carlo Methods in Biology, 2nd edition, Chapman and Hall, London, 1997.

Nagai, T., Kato, T., Moritani, N., Izumi, H., Terada, Y., and Mitsui, M.: Proposal of hybrid tsunami monitoring network system consisted of offshore, coastal and on-site wave sensors, Coast. Eng. J., 49, 63-76, 2007.

Okal, E. A., Piatanesi, A., and Heinrich, P.: Tsunami detection by satellite altimetry, J. Geophys. Res., 104, 599-615, 1999.

Powell, B. S. and Leben, R. R.: An optimal filter for geostrophic mesoscale currents from along-track satellite altimetry, J. Atmos. Ocean. Tech., 21, 1633-1642, 2004.

Rowan, L.: Tsunami and its shadow, Science, 304, p.1569, 2004.
Schindelé, F., Loevenbruck, A., and Hébert, H.: Strategy to design the sea-level monitoring networks for small tsunamigenic oceanic basins: the Western Mediterranean case, Nat. Hazards Earth Syst. Sci., 8, 1019-1027, 2008, http://www.nat-hazards-earth-syst-sci.net/8/1019/2008/.

Sladen, A. and Hébert, H.: On the use of satellite altimetry to infer the earthquake rupture characteristics: application to the 2004 Sumatra event, Geophys. J. Int., 172, 707-714, doi:10.1111/j.1365-246X.2007.03669.x, 2008.

Smith, W. H. F., Scharroo, R., Titov, V. V., Arcas, D., and Arbic, B. K.: Satellite altimeters measure tsunami, Oceanography, 18, 11-13, 2005.

Song, T. Y., Ji, C., Fu, L.-L., Zlotnicki, V., Shum, C. K., Yi, Y., and Hjorleifsdottir, V.: The 26 December 2004 tsunami source estimated from satellite radar altimetry and seismic waves, Geophys. Res. Lett., 32, L20601, doi:10.1029/2005GL023683, 2005.

Stein, S. and Okal, E. A.: Speed and size of the Sumatra earthquake, Nature, 434, 581-582, doi:10.1038/434581a, 2005.

Synolakis, C. E. and Bernard, E. N.: Tsunami science before and beyond Boxing Day 2004, Philos. T. Roy. Soc. A., 364, 22312265, doi:10.1098/rsta.2006.1824, 2006.

Titov, V., Rabinovich, A. B., Mofjeld, H. O., Thomson, R. E., and González, F. I.: The global reach of the 26 December 2004 Sumatra tsunami, Science, 309, 2045-2048, doi:10.1126/science/1114576, 2005.

Troitskaya, Y. I.: Modulation of the growth rate of short surface capillary-gravity wind waves by a long wave, J. Fluid Mech., 273, 169-187, 1994.

Troitskaya, Y. I. and Ermakov, S. A.: Recording of the December 26, 2004 tsunami in the open ocean based on variations in radar scattering section, Dokl. Earth Sci., 405A, 1384-1387, 2005.

Troitskaya, Y. I. and Ermakov, S. A.: Manifestations of the Indian Ocean tsunami of 2004 in satellite nadir-viewing radar backscattering variations, Int. J. Remote Sens., 29, 6361-6371, doi:10.1080/01431160802175348, 2008.

Walker, D. A.: Observations of tsunami "shadows": A new technique for assessing tsunami wave heights?, Science of Tsunami Hazards, 14, 3-11, 1996.

Wand, M. P. and Jones, M. C.: Kernel Smoothing, Chapman and Hall, London, 1995.

Wei, Y., Bernard, E. N., Tang, L., Weiss, R., Titov, V. V., Moore, C., Spillane, M., Hopkins, M., and Kânoğlu, U.: Realtime experimental forecast of the Peruvian tsunami of August 2007 for US coastlines, Geophys. Res. Lett., 35, L04609, doi:10.1029/2007GL032250, 2008.

Witter, D. L. and Chelton, D. B.: A geosat altimeter wind speed algorithm and a method for altimeter wind speed algorithm development, J. Geophys. Res., 96, 8853-8860, 1991.

Zaichenko, M. Y., Kulikov, E. A., Levin, B. V., and Medvedev, P. P.: On the possibility of registration of tsunami waves in the open ocean with the use of a satellite altimeter, Oceanology, 45, 194201, 2005. 